\title{
In memoriam: Professor Philip H. Quanjer
}

\author{
Professor Philip H. Quanjer, Emeritus Professor of Physiology, Leiden \\ University, The Netherlands; co-founder of the European Respiratory Society \\ and European Respiratory Journal
}

Janet Stocks ${ }^{1}$ and Irene Steenbruggen ${ }^{2}$

Affiliations: ${ }^{1}$ UCL Great Ormond Street Institute of Child Health, London, UK. ${ }^{2}$ Pulmonary Laboratory, Isala, Zwolle, The Netherlands.

Correspondence: Janet Stocks, UCL Great Ormond Street Institute of Child Health, 30 Guilford St, London WC1N 1EH, UK. E-mail: j.stocksवucl.ac.uk

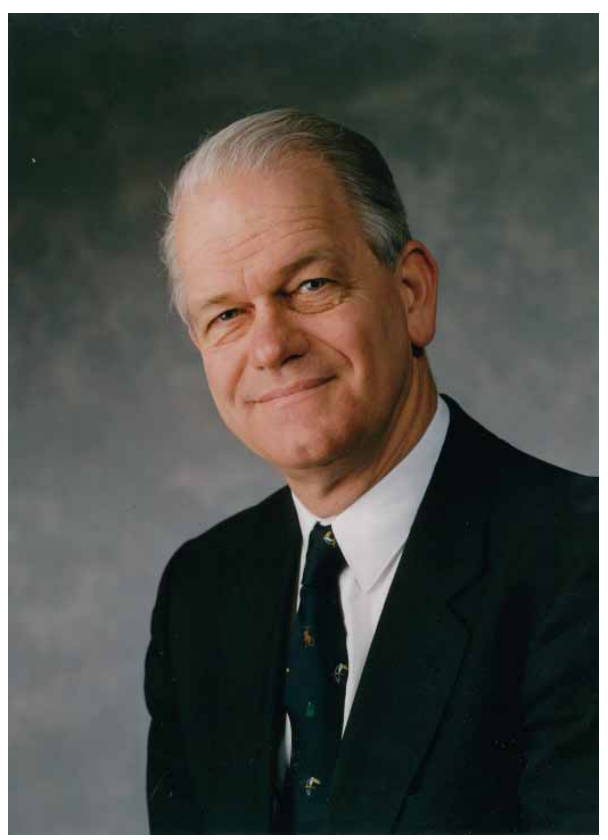

\begin{abstract}
A great sense of loss and sadness marked the recent death of Philip Quanjer, who passed away peacefully at his home in Nijverdal, the Netherlands on July 26, 2017 after a long and courageous battle against cancer, during which he defied all odds in order to complete the tasks he had set himself. Philip was a highly respected member of the global respiratory community, who devoted his life to understanding and describing lung health, remaining highly active in his field up to a few weeks before his death. Indeed, after "retiring" in 1997, he went on to publish a further 90 papers, an astonishing 55 of which being published during the last five years of his life. His efforts since the 1980s to improve the standard of lung function testing and develop more reliable reference values with which to interpret the results of such tests have won him international acclaim and immense respect and admiration from the global respiratory community. Such developments were essential in order to improve early detection of respiratory disease, irrespective of age, sex or ethnic background, and to clarify what factors impact negatively on lung development.
\end{abstract}

Philip was born on September 12, 1936 in Pontianak (Netherlands East Indies, now Indonesia) and spent his formative years in a Japanese concentration camp (where he learnt to swim in crocodile infested 
rivers!) until liberation in 1945. His first two years of formal education, which did not commence until he was nine years of age, were spent in Thailand and Indonesia before his family returned to the Netherlands in 1948. Philip met the love of his life and future wife, Else Meijerink, while they were both high school students. They married in 1960, while he was still a student at Groningen University medical school (1955-1963), had four children (two sons and two daughters) and recently celebrated their 57th wedding anniversary. Philip was drafted into military service in 1964, serving the Royal Navy at the Navy's diving centre, before embarking on a residency in internal medicine at Groningen University Hospital, which he completed in 1970.

Philip's interest in respiratory physiology was evident from an early age, with 2.5 years of his medical school training devoted to physiological work. This was followed by a period of extensive research into exercise-induced asthma and the pharmacokinetics of patients with airflow limitation while he was a young clinician, leading to the award of his $\mathrm{PhD}$ on "Plethysmographic evaluation of airway obstruction" in 1970. After holding various consultant posts in the Netherlands, he was appointed Head of the Respiratory Division at Leiden University in 1972, were he was awarded his chair in Respiratory Physiology in 1980 and where he continued to work until his "retirement" in 1997.

As well as being a very thorough, astute and wise reviewer of the scientific literature, Philip was an associate editor/board member for several international journals. He also contributed to innumerable national and international committees, task forces and working parties during his lifetime, including the European Society for Clinical Respiratory Physiology (SEPCR: 1975-1990) of which he became president in 1985. He was a co-founder of both the European Respiratory Journal and the European Respiratory Society (ERS), having played a key role in the merger of both the European Journal of Respiratory Disease and Bulletin Européen Physiopathologie Respiratoire in 1987, and the SEPCR and the European Society of Pneumology (SEP) in 1990. He not only participated in several American Thoracic Society (ATS) task forces in the 1990s, but made a very active contribution to the ERS/ATS task force on infant lung function (1992-1996), the first such task force to be organised jointly between the two societies [1]. In 1995, Philip was honoured by ERS to deliver the prestigious Sadoul lecture. Furthermore, it was Philip who was the driving force behind the creation, in 1994, of the section for lung function technologists and scientists within the ERS which, after including physiotherapists and nurses, became assembly 9. In recognition of his huge contributions to the respiratory community worldwide, Philip received a Lifetime Achievement Award from the Association of Respiratory Technicians and Physiologists (ARTP, UK) in 2013.

Philip was an excellent speaker, a brilliant, enthusiastic and committed teacher, an outstanding physician and an intellectually rigorous scientist, characterised by the highest standards of both personal and professional integrity. He was one of the pioneers in strengthening cooperation in the fields of science and technology across Europe, which started within the European Coal and Steel Community (ECSC), the roots of the European Union. From 1978 until 1994, Philip was the scientific secretary of the ECSC working party on "Standardisation of Lung Function Tests".

One of Philip's key characteristics was his ability to see the "big picture", without ever losing attention to the fine detail. It was he who realised over 40 years ago that adult respiratory disease frequently originated from early life exposures, thereby stimulating his interest in lung growth and development. With his active, enquiring mind, he managed to cross bridges between pulmonology, paediatrics, physiology, epidemiology, engineering, information technology and statistics, always resorting to self-teaching if he couldn't find anyone to show him the ropes of a new discipline!

As recently described in "A tribute to Philip Quanjer" [2], Philip's name will always be associated with lung function reference values. This started with the publication of the first European documents on standardisation of lung function tests, which included recommended sets of reference values in 1983 [3], and culminated in the publication of "Multi-ethnic reference values for the 3-95 year age range" in 2012 [4], undertaken as part of the ERS Global Lung Function Initiative (GLI). The GLI 2012 equations have been endorsed by all the major respiratory societies world-wide, incorporated into most commercially available lung function software and are now in widespread use (http://www.ers-education.org/guidelines/ global-lung-function-initiative.aspx). The GLI network, which Philip pioneered and played a pivotal (completely unfunded) role in, represents an outstanding example of international collaboration and altruism which continues to grow in both breadth and strength and which will be a lasting legacy to Philip's memory [5]. As part of his efforts to improve the way in which lung function tests were reported, and to prevent unnecessary and potentially detrimental treatment in older but otherwise healthy individuals, Philip was a fierce defendant of the concept of "healthy ageing" by improving the definition and description of what is and is not normal based on the use of z-scores rather than "percent of predicted" and "fixed cut-offs" when interpreting results. 
After his retirement, Philip also continued working on projects such as his open-access SpirXpert website which aims to promote understanding of respiratory physiology and pathophysiology, with emphasis on the measurement and interpretation of spirometric test results. The importance of this website (which was managed by Philip up to the time of his death and which has been translated into many languages), has been recognised by the ERS, who will now take over hosting this resource and continue to maintain it as a free and open access resource for future generations (http://spirxpert.ers-education.org).

Philip was however far, far more than the sum of all these amazing clinical and academic achievements, as all who had the privilege and joy of working with him can testify. It is difficult to describe the magnitude of his influence on the respiratory community around the world, but the terms "rock" and "giant" have been cited frequently in recent weeks. He was a wonderful mentor, not only to the $18 \mathrm{PhD}$ students whom he supervised, but to a wide range of medical, physiological, nursing, diving and technical students and, during latter years, to anyone around the world who sought his help and advice. Those who met Philip were immediately impressed not only by his infectious enthusiasm for whatever problem needed tackling, but by his wisdom and vision, combined with the drive and determination to complete the task in hand.

Philip's ability to "see the big picture, while paying close attention to the detail" extended into his private life and was perhaps best epitomised by his love of the natural world (including the beautiful garden that he and Else created and nurtured) and by his passion for wildlife photography. The latter resulted in many magnificent images being shared between family and friends via his and his son's websites, not only of the superb animals sighted during his annual safaris to Africa, but of a wide variety of exquisite birds, insects and flowers sighted both at home and abroad. He was a truly all-round gifted human being who always made the best of life, whom we have much to learn from.

As part of his "retirement" activities, Philip created and led an informal network of like-minded, free-spirited respiratory physiologists who could exchange ideas and discuss controversial issues within a safe and friendly forum. He named this the "Pulmonaria group" and during one of his many exchanges wrote to tell us; "The Pulmonaria is in bloom in my garden. There are various species. The one in my garden is the Pulmonaria officinalis. In spring, it produces small bunches of pink flowers which turn to blue-purple ("oxygenated and hypoxic blood"). The plant has been cultivated for centuries as a medicinal herb, the ovate spotted leaves held to be representative of diseased lungs, following the Doctrine of Signatures."

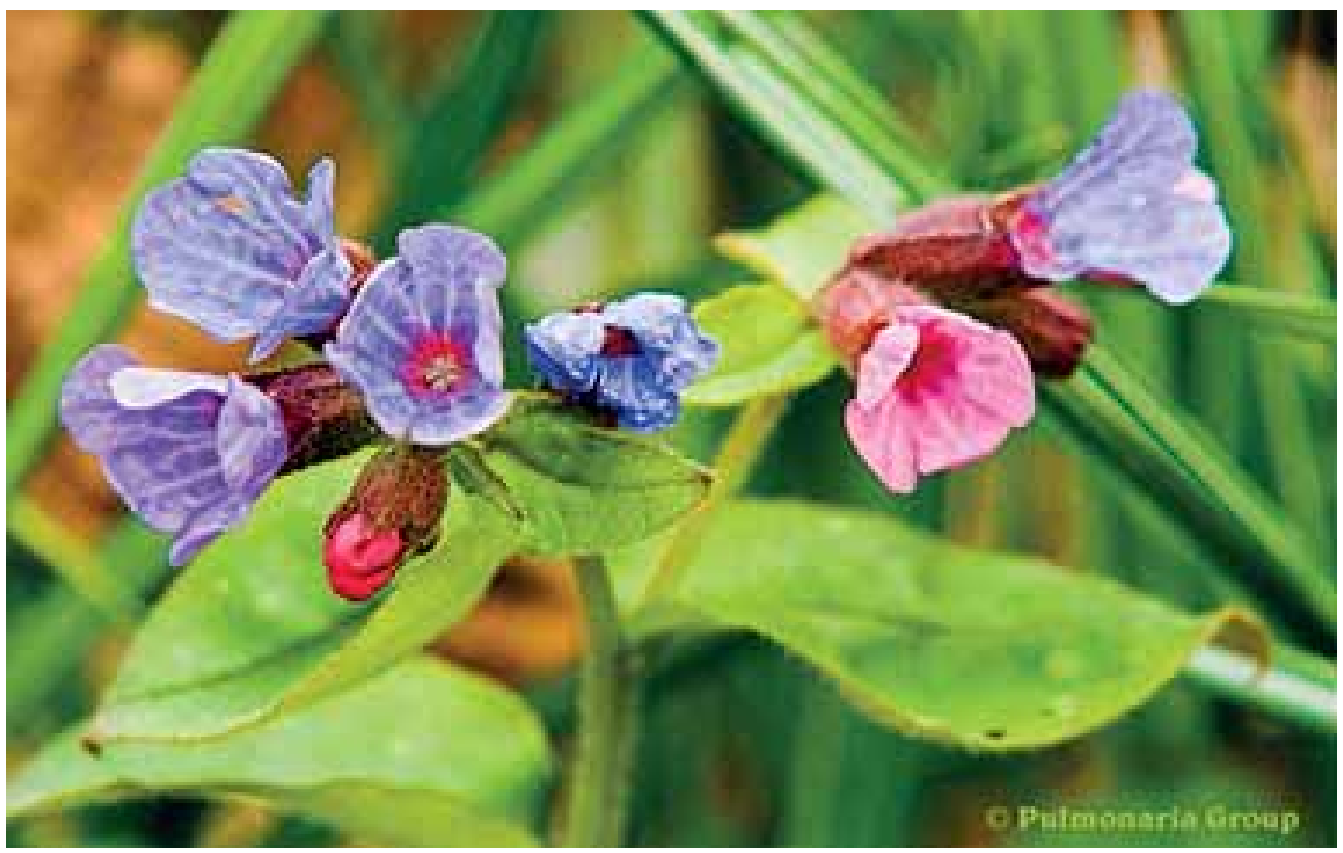

Philip was a truly remarkable man, whose life and work were characterised by altruism and international collaboration. He was an intellectual giant, with an amazing mind, and a clarity of purpose and vision, without the slightest hint of intellectual arrogance. He had a charisma, kudos and gravitas that few achieve and was a man whose understanding and beliefs were wrapped in justice, integrity, honesty and passion. 
His love of meeting people from all over the world, of talking to them and listening to their views, was captured in his final, very moving farewell message to his colleagues, where he noted that "feelings of friendship and respect have always transcended geographical barriers."

Since his death many colleagues expressed their gratitude, admiration and respect for Philip, noting how much of an impact he had made on their lives, even if they had only met him occasionally. All have mentioned that it has been a privilege to have known and worked with such a leading light of our profession and a truly international citizen. It is not only his vast collection of scientific works so freely shared with others that will provide a legacy for generations to come, but memories of Philip as a wonderful human being. If it is difficult for us, as a respiratory community, to imagine Philip not being around to discuss such a wide range of issues, how much harder for Else, his children and grandchildren, all of whom he loved so much, and to whom we offer our sincerest condolences.

Philip's death represents the sad loss of an amazing individual whose contribution to respiratory physiology and science is immeasurable. He has certainly left his mark on our world, which is a better place for him having lived in it, and he will not only be remembered with fondness and gratitude by all who knew him personally, but referred to in admiration by generations of respiratory physiologists and practitioners yet to come.

\section{References}

1 Quanjer PH, Sly PD, Stocks J. Respiratory function measurements in infants: symbols, abbreviations and units. Eur Respir J 1995; 8: 1039-1056.

2 Merkus P. A tribute to Philip Quanjer. Pediatr Pulmonol 2014; 49: 103-105.

3 Quanjer PH. Standardized lung function testing. Report working party. Bull Eur Physiopathol Respir 1983; 19: Suppl 5, 1-95.

4 Quanjer PH, Stanojevic S, Cole TJ, et al. Multi-ethnic reference values for spirometry for the 3-95-yr age range: the global lung function 2012 equations. Eur Respir J 2012; 40: 1324-1343.

5 Cooper B, Stocks J, Hall GL, et al. The Global Lung function Initiative (GLI) Network: bringing the world's respiratory reference values together. Breathe (Sheffield, England) 2017; 13: e56-e64. 